\title{
RANCANG BANGUN DC GENERATOR MAGNET PERMANEN TIPE AXIAL-FLUX PERMANENT MAGNET (AFPM) MENGGUNAKAN RANGKAIAN PENYEARAH
}

\author{
Hartono B.S, I M. W. Kastawan dan Asep Barkah Muhadi \\ Jurusan Teknik Konversi Energi - Politeknik Negeri Bandung \\ Email : hartono@esi-labs.com,wiwit.kastawan@polban.ac.id
}

\begin{abstract}
Abstrak
DC Generator magnet permanen tipe fluk aksial atau Axial Fluxs Permanent Magnet (AFPM) menggunakan rangkaian penyearah ditujukan sebagai sumber daya input rangkaian inverter yang akan merubah menjadi sumber daya AC. Generator menggunakan magnet permanen sebagai sumber eksitasinya sehingga konstruksinya relatif sederhana jika dibandingkan dengan genertor radial konvensional pada umumnya. Rancang bangun generator AFPM satu-fasa tipe single sidded slotted menggunakan magnet permanen memiliki karakteristik keluaran yang sangat ditentukan oleh jenis permanen magnet yang digunakan. Ada beberapa jenis magnet permanen yang dapat digunakan pada generator magnet permanen seperti jenis magnet permanen jenis ferrit/keramik dan Neodymium ( $\mathrm{NdFeB}$ ).

Bagaimana melakukan rancang bangun DC generator AFPM menggunakan rangkaian penyearah dan melakukan pengujian karakteristik penggunaan magnet permanen khususnya pada unjuk kerja tegangan keluaran generator AFPM, untuk melihat bagaimana distribusi fluks magnet terhadap kumparan jangkar, menjadi fokus penelitian ini.

Dari pengujian berskala laboratorium diperoleh tegangan keluar tanpa beban dari generator yang berbentuk sinus dengan tegangan berkisar antara 17,5 - 79,5 volt. Tegangan keluaran berbeban berkisar antara $21 \mathrm{~V}-48 \mathrm{~V}$ dengan daya keluaran hingga $76 \mathrm{~W}$, pada variasi putaran antara $100 \mathrm{rpm}$ hingga $450 \mathrm{rpm}$.
\end{abstract}

Kata kunci : Generator AFPM, Magnet Neodymium, stator, rotor

\section{PENDAHULUAN}

Generator Axial Fluxs Permanent Magnet (AFPM) merupakan generator sederhana yang mampu bekerja pada putaran rendah, merupakan tipe generator yang cocok digunakan untuk aplikasi turbin angin ataupu turbin air [1]. Generator ini terdiri atas bagian stator dan rotor, bagian stator terdiri atas kumparan kawat tembaga, dan bagian rotor terdiri atas magnet permanen dan berprinsip kerja hukum Faraday.

Ada beberapa jenis magnet permanen antara lain barium ferit (BaF12O19) dan neodyum iron boron (NdFeB). Berdasarkan pengukuran $\mathrm{NdFeB}$ memiliki fluks sepuluh kali lebih besar dibanding BaF12O19 [2]. Oleh karena itu magnet permanen dengan jenis $\mathrm{NdFeB}$ sangat cocok digunakan pada generator menggunakan magnet permanen. Tegangan dan daya keluaran generator merupakan indikator penting untuk mengevaluasi kualitas generator magnet permanen. Bentuk gelombang berkaitan erat dengan besarnya celah udara medan magnet gelombang sinusoidal pada generator, sehingga optimasi struktur generator dengan mengatur besarnya celah udara medan magnet gelombang sinusoidal merupakan metode yang efektif untuk meningkatkan kualitas tegangan keluaran generator.

Pada penelitian ini akan dilakukan rancang bangun generator AFPM tipe single sided slotted dan melakukan pengujian karakteristik tegangan dan daya keluaran DC yang dihasilkan generator. Rancang bangun generator ditujukan untuk dihubungkan dengan peangkat inverter sehingga tegangan keluaran generator akan disearahkan menggunakan rangkaian dioda.

\section{METODOLOGI}

\section{Generator Axial Flux Permanent Magnet} (AFPM)

Pada generator AFPM, magnet permanen berfungsi sebagai pengganti kumparan medan pada rotor sehingga tidak diperlukan adanya pembangkit (exciter) dan sikat dengan arah aliran fluks secara tegak lurus kumparan [3].

Prinsip kerja generator AFPM berdasarkan hukum faraday dimana pada saat rotor diputar, fluks magnet akan memotong 
setiap kumparan yang terdapat pada piringan stator sehingga terjadi ggl (gaya gerak listrik) induksi pada kumparan di stator. Berdasarkan proses tersebut maka timbul tegangan, dalam menentukan nilai tegangan rata-rata yang dibangkitkan generator dapat digunakan persamaan hukum faraday berikut [4][5]:

$$
E_{\text {rata-rata }}=N \frac{\Delta o}{\Delta t}
$$

dimana :

$E_{\text {rata-rata }}=$ tegangan rata-rata yang dibangkitkan pada belitan (V)

$\Delta \varnothing \quad=$ perubahan fluks pada suatu waktu tertentu $(\mathrm{Wb})$

$\Delta t \quad=$ waktu ketika fluks berubah (s)

$N \quad=$ jumlah lilitan

Adapun hubungan antara putaran dan frekuensi generator dapat dirumuskan pada persamaan berikut :

$$
n=\frac{120 f}{p}
$$

dimana :

$$
\begin{array}{ll}
n & =\text { putaran }(\mathrm{RPM}) \\
f & =\text { frekuensi }(\mathrm{Hz}) \\
p & =\text { jumlah kutub }
\end{array}
$$

Selain itu, dalam menentukan tegangan rms yang dibangkitkan generator dapat menggunakan persamaan berikut :

$$
E_{r m s}=4,44 f N \emptyset_{m}
$$

dimana :

$$
\begin{array}{ll}
E_{r m s} & =\text { tegangan efektif dibangkitkan } \\
& \text { belitan (V) } \\
f & =\text { frekuensi }(\mathrm{Hz}) \\
\emptyset_{m} & =\text { fluks maksimum }(\mathrm{Wb}) \\
N & =\text { jumlah belitan }
\end{array}
$$

\section{Konstruksi Generator Axial Flux}

Permanent Magnet

Sama seperti generator pada umumnya generator fluks aksial memiliki stator dan rotor sebagai komponen generator. Kumparan pada stator terbagi menjadi dua macam yaitu, kumparan tersusun secara overlapping dan non-overlapping. Pada stator dengan susunan kuparan secara overlapping, kumparan diletakkan tumpang tindih antara satu kumparan dengan kumparan lainnya. pemasangan kumparan pada bagian stator dapat dilakukan dengan dua cara. Adapun cara yang dilakukan yaitu, dengan meletakkan kumparan pada permukaan piringan stator (slotless) atau dengan membenamkan kumparan kedalam piringan stator (slotted), seperti terlihat pada gambar 1. [6]

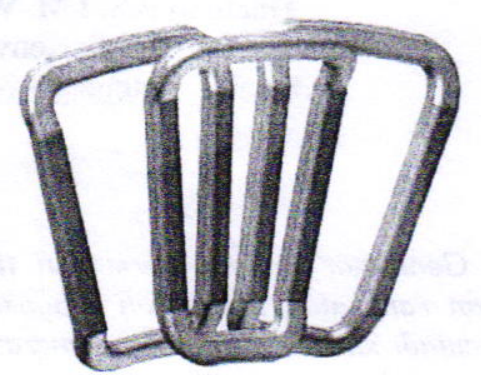

(a)

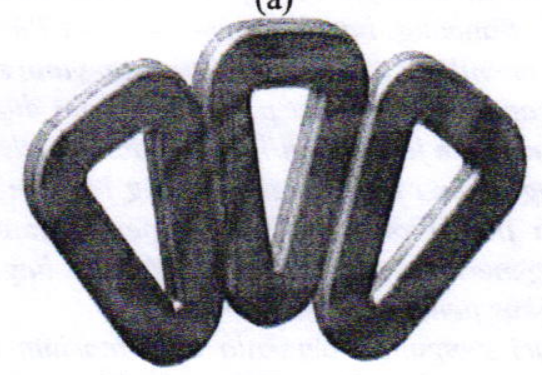

(b)

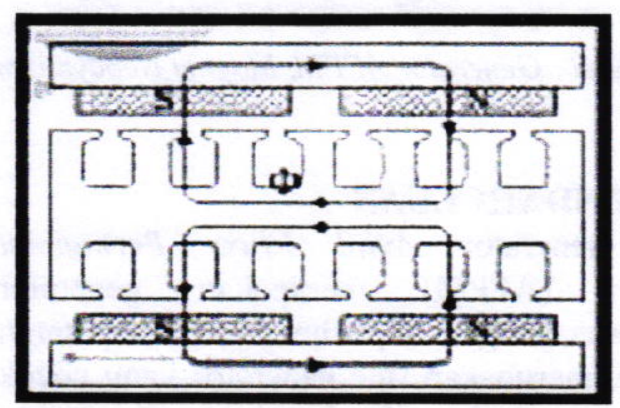

(c)

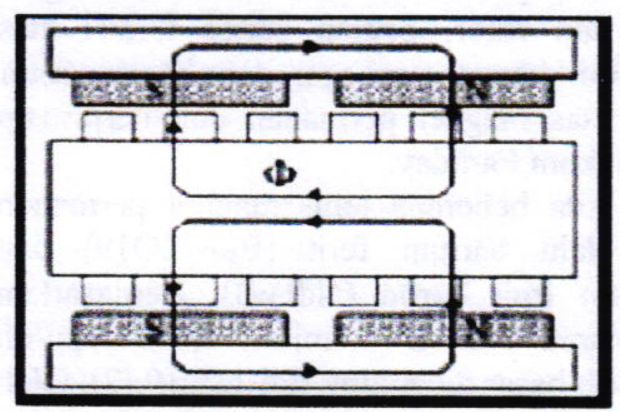

(d)

$\begin{array}{lll}\text { Gambar 1. } & \text { a. Overlaping } \quad \text { b. Non- } \\ \text { overlapping } & \text { c. Slotted } & \text { d. Slotless }\end{array}$

Bagian rotor pada generator fluks aksial susunan magnet permanen dapat dilakukan secara surface-mounted atau secara embedded [7]. Rotor dengan tipe surface-mounted memiliki komponen magnet permanent yang diletakkan pada permukaan piringan rotor, 
seperti terlihat pada gambar 2. Rotor dengan tipe surface-mounted memiliki komponen magnet permanen yang diletakkan pada permukaan piringan rotor. Hal ini membuat pemasangan magnet permanen menjadi lebih mudah dibandingkan dengan tipe embedded.Untuk pemasangan magnet dengan tipe embedded diperlukan suatu ruangan atau slot-slot pada bagian piringan rotornya. Selain itu, pada tipe embedded memiliki suatu keunggulan berupa celah udara antara piringan stator dan rotor yang dapat diatur serapat mungkin.

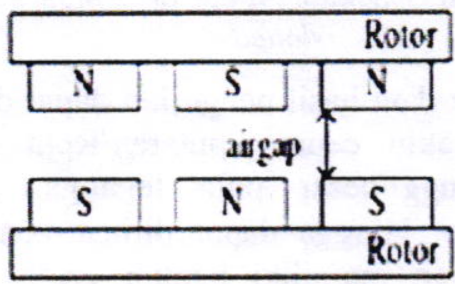

(a)

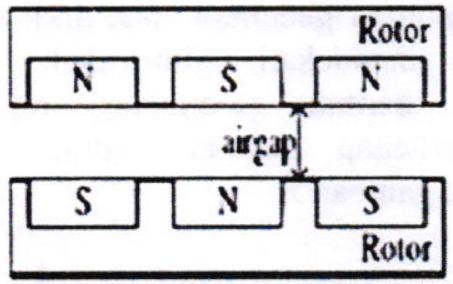

(b)

Gambar 2. rotor tipe a. surface-mounted b. embedded.

Bentuk magnet permanen sangatlah bervariasi sehingga pada generator fluka aksial dapat digunakan berbagai macam konfigurasi konstruksi magnet seperti trapezoid, circular, dan semicircular, tampak pada gambar 3.
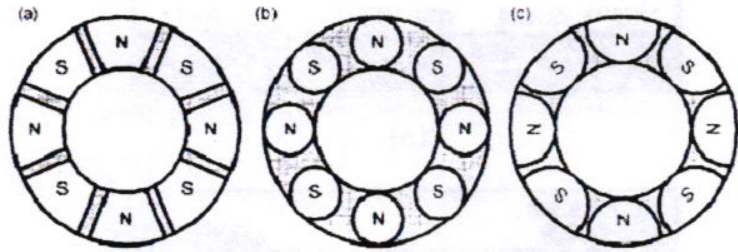

Gambar 3. Bentuk-bentuk magnet a.Trapezoidal

$$
\text { b. Circular }
$$

c. Semicircular

\section{Tipe Magnet Permanen}

Magnet permanen akan menghasilkan medan magnet yang akan menginduksi kumparan sehingga akan dihasilkan arus induksi. Besarnya medan magnet akan menentukan besarnya arus induksi yang dihasilkan. Ada beberapa tipe magnet permanen antara lain :
- Magnet Neodymium $\left(\mathrm{N}_{\mathrm{d}} \mathrm{F}_{\mathrm{e}} \mathrm{B}\right)$, merupakan sejenis magnet tanah jarang yang terbuat dari campuran logam Neodymium.

- Magnet Samarium-Cobalt, terbuat dari paduan samarium dan kobalt.

- Ceramic Magnet, merupakan magnet kramik memiliki sifat daya tarik yang kuat, output besar, anti karat dan murah. Sifatnya permanen tapi mudah patah atau pecah jika terkena benturan.

- Alnico Magnet, memiliki sifat magnetis yang lebih lemah bila dibandingkan dengan jenis magnet lainnya, output lebih rendah namun dinamis dan sustainable, sifatnya semi permanen karena kadar ferrousnya tidak mendominasi, tidak mudah pecah atau patah jika terkena benturan.

\section{Spesifikasi Generator AFPM tipe Single Sided Slotted}

Generator AFPM tipe single sided slotted yang telah dirancang berusaha dibuat bekerja optimal pada frekuensi $50 \mathrm{~Hz}$. Untuk mendapatkan frekuensi $50 \mathrm{~Hz}$ generator harus di putar pada putaran nominal dan untuk mengetahui putaran nominal dari generator dapat ditentukan dengan mengetahui jumlah kutub magnet dari generator tersebut. Pada bagian rotor generator AFPM tipe single sided slotted terdapat 20 buah magnet permanen, maka kecepatan putaran yang diperlukan untuk mendapatkan frekuensi $50 \mathrm{~Hz}$ adalah sebagai berikut.

$$
\begin{aligned}
n & =\frac{120 \times f}{p} \\
& =\frac{120 \times 50 h z}{20} \\
& =\frac{6000}{20} \\
& =300 \mathrm{RPM}
\end{aligned}
$$

Dari hasil perhitungan diatas dapat diketahui bahwa putaran nominal pada generator AFPM tipe single sided slotted adalah 300 RPM. Pada stator generator AFPM yang dibuat mampu menampung lilitan sebanyak 2500 lilitan pada diameter $1 \mathrm{~mm}$ dengan jumlah dari tiap kumparan 250lilit. Adapun parameter-parameter dimensi dari piringan rotor dan piringan stator dari yang telah dirancangpada Generator AFPM tipe single sided slotted dapat dilihat pada Tabel 1 berikut ini. 
Tabel 1. Parameter-parameter Dimensi piringan Generator AFPM

\begin{tabular}{|l|c|c|}
\hline \multicolumn{1}{|c|}{ Parameter } & Simbol & Nilai \\
\hline Jari-jari generator & $R$ & $200 \mathrm{~mm}$ \\
Tebal piringan rotor & $t_{\text {rotor }}$ & $10 \mathrm{~mm}$ \\
Tebal piringan stator & $t_{\text {stator }}$ & $20 \mathrm{~mm}$ \\
Tebal belitan jangkar & $t_{\text {belitan }}$ & $17 \mathrm{~mm}$ \\
Jumlah Belitan & & 10 belitan \\
Jumlah lilitan & $N_{\text {fasa }}$ & 2500 lilitan \\
Diameter kawat lilitan & $d_{\text {kawat }}$ & $1 \mathrm{~mm}$ \\
\hline
\end{tabular}

Pada kawat tembaga dengan diameter $1 \mathrm{~mm}$ memiliki kuat hantar Arus sebesar 1,57-2,36 A. Apabila diasumsikan bahwa nilai arus yang dihantarkan oleh kawat tembaga adalah sebesar 2,36 Ampere, dan Tegangan dengan lilitan kumparan 2500 lilit yang dihasilkan pada putaran $300 \mathrm{Rpm}$ adalah 52,4 Volt. Spesifikasi generator AFPM yang akan dibuat memiliki spesifikasi tampak pada tabel 2 .

Tabel 2.spesifikasigenerator AFPM tipe single sided slotted.

\begin{tabular}{|l|c|}
\hline \multicolumn{1}{|c|}{ Parameter } & Nilai \\
\hline Putaran & $300 \mathrm{RPM}$ \\
Tegangan (berbeban) & 52,4 Volt \\
Frekuensi & $50 \mathrm{~Hz}$ \\
Jumlah Kutub Magnet & $10 \mathrm{Buah}$ \\
\hline
\end{tabular}

\section{HASIL PENGUJIAN \\ Pengujian Tanpa Beban}

Hasil pengujian generator AFPM tanpa beban berdasarkan nilai putaran dengan melakukan pengukuran tegangan keluaran yang dihasilkan seperti tampak pada Tabel 3 .

Tabel 3. Hasil pengujian putaran terhadap tegangan keluaran generator

\begin{tabular}{|c|c|c|}
\hline No. & n (Rpm) & Vac (Volt) \\
\hline 1. & 100 & 17,5 \\
\hline 2. & 200 & 35,0 \\
\hline 3. & 300 & 53,5 \\
\hline 4. & 400 & 70,5 \\
\hline 5. & 450 & 79,5 \\
\hline
\end{tabular}

Berdasarkan persamaan (3) dimana nilai $N$ sebagai jumlah lilitan dan $\emptyset_{m}$ sebagai nilai fluks yang tidak berubah nilainya atau konstan, maka nilai yang mempengaruhi besar $E_{r m s}$ adalah variable $f$ (frekwensi) yang berubah berdasarkan banyaknya putaran, dari pesamaan (2). Hasil pengukuran tegangan keluaran generator dapat dilihat bahwa pada putaran 100 hingga $450 \mathrm{Rpm}$ mampu menghasilkan tegangan sebesar 17,5 Volt hingga 79,5 Volt pada kumparan sebanyak 2500 lilit, tampak pada tabel 3.

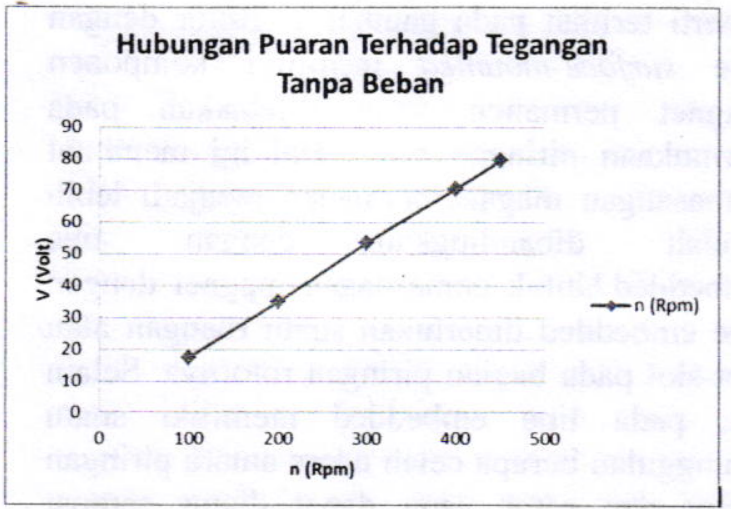

Gambar 4. Grafik hubungan tegangan dan putaran tanpa beban Generator AFPM tipe single sided slotted

Berdasarkan data hasil pengujian dapat dilihat bahwa semakin cepat putaran/Rpm maka semakin tinggi/besar pula tegangan yang dibangkitkan. Hingga dapat dilihat kenaikan nilai tegangan memiliki bentuk grafis yang hampir linier, gambar 4. Hasilkan profil tegangan keluaran generator memiliki bentuk gelombang mendekati sinusoidal. Hasil pengukuran bentuk gelombang tegangan keluaran terhadap putaran (Rpm) seperti tampak pada gambar 5 .

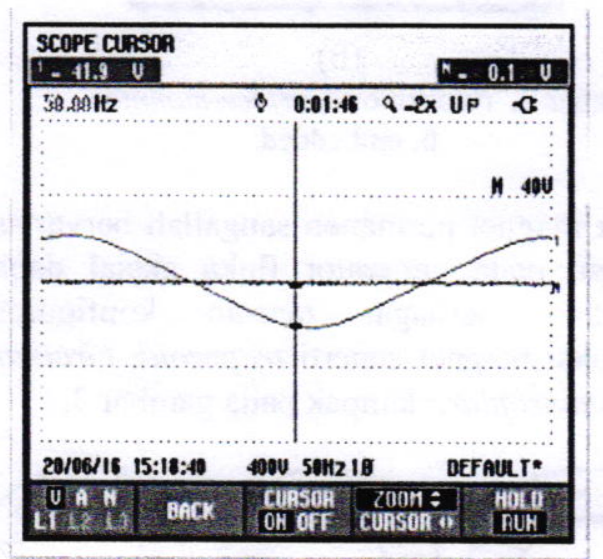

(a)

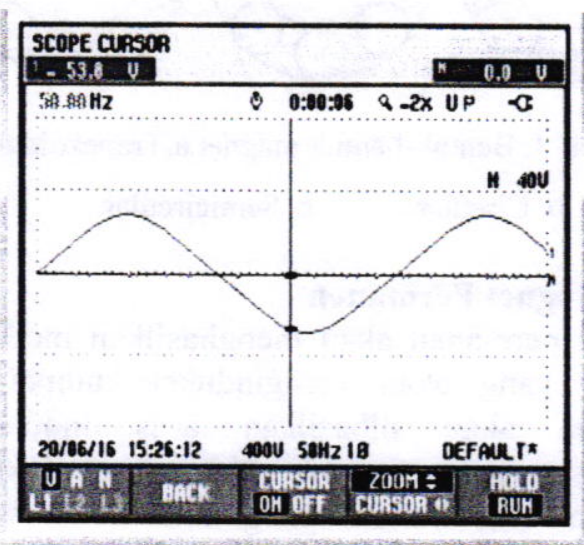

(b) 


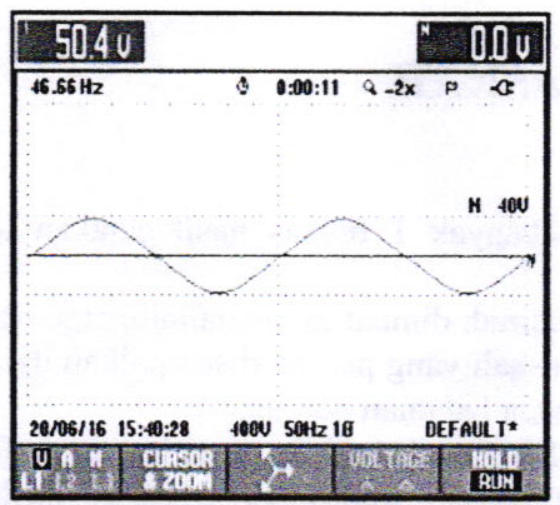

(c)

Gambar 5. Besaran dan bentuk tegangan keluaran generator AFPM pada, a. $100 \mathrm{rpm} \quad$ b. $200 \mathrm{rpm}$ c. $300 \mathrm{rpm}$

\section{Pengujian Dengan Beban}

Sebagaimana yang menjadi tujuan penelitian ini, generator AFPM akan mensuplay rangkaian inverter yang memiliki spesifikasi jangkauan tegangan masukan antara $21 \mathrm{~V}-48 \mathrm{~V}$, maka diharapkan tegangan keluaran generator setelah disearahkan harus masuk dalam jangkauan tegangan tersebut. Oleh sebab itu dilakukan pengujian dengan beban untuk melihat kemampuan generator ketika berbeban.

Rangkaian pengujian untuk kondisi berbeban seperrti tampak pada gambar 6 .

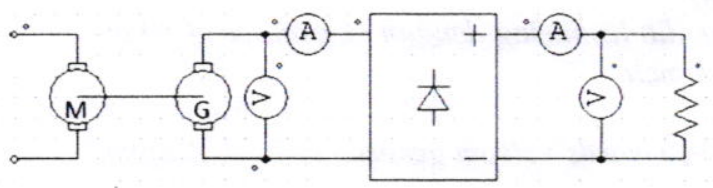

Gambar 6. Rangkaian pengujian berbean

Tabel 4. pengujian pada tahanan beban resistor $31,5 \Omega$

\begin{tabular}{|c|c|c|c|c|c|c|c|}
\hline Ne. & $\begin{array}{c}\text { N } \\
(\mathbf{R p m})\end{array}$ & $\begin{array}{c}\text { Vac } \\
\text { (Volt) }\end{array}$ & $\begin{array}{c}\text { Iac } \\
(\mathbf{A})\end{array}$ & $\begin{array}{c}\text { Pac } \\
(\text { Watt) }\end{array}$ & $\begin{array}{c}\text { Vde } \\
\text { (Volt) }\end{array}$ & $\begin{array}{c}\text { Idc } \\
(\mathbf{A})\end{array}$ & $\begin{array}{c}\text { Pde } \\
\text { (Watt) }\end{array}$ \\
\hline 1 & 100 & 12 & 0.1 & 1.2 & 10 & 0.35 & 3.5 \\
\hline 2. & 200 & 25 & 0.65 & 16.25 & 21.5 & 0.8 & 17.2 \\
\hline 3 & 300 & 36 & 1.53 & 5.08 & 33 & 1.1 & 36.3 \\
\hline 4 & 400 & 49 & 1.58 & 77.42 & 42.5 & 1.45 & 61.625 \\
\hline 5 & 450 & 58 & 2 & 116 & 48 & 1.6 & 76.8 \\
\hline
\end{tabular}

Hasil pengujian seperti tampak pada tabel 4 . Memperlihatkan tegangan keluaran DC sebesar $21 \mathrm{~V}$ pada putaran $200 \mathrm{rpm}$ dan $48 \mathrm{~V}$ pada putaran 450rpm, ini sesuai dengan spesifikasi tegangan masukan inverter. Sementara daya yang dihasilkan mencapai 76Watt DC pada 450rpm.

\section{KESIMPULAN}

Dari hasil pengujian dan analisis yang telah dilakukan penulis. Maka dari itu dapat ditarik kesimpulan bahwa pada rancang bangun Generator Axials Fluxs Permanent Magnet tipe single sided slotted dengan menggunakan lilitan kawat berdia meter $1 \mathrm{~mm}$ sebanyak 2500 lilit menghasilkan tegangan sebesar 17,5 Volt hingga 79,5 Volt pada putaran $100 \mathrm{Rpm}$ hingga $350 \mathrm{Rpm}$, dan dan nilai frekuensi sekitar $50 \mathrm{~Hz}$.

Tegangan keluaran berbeban berkisar antara $21 \mathrm{~V}-48$ volt sesuai dengan spesifikasi kebutuhan tegangan masukan inverter. Akan tetapi daya keluaran masih perlu ditingkatkan.

\section{DAFTAR PUSTAKA}

[1] Hasyim Asy'ari, Dhanar Yuwono Aji, dan Fahrur Septian Candra, "Desain Generator Tipe Axial Kecepatan Rendah dengan Magnet Permanen", Jurnal Emitor Vol. 13 No. 02 ISSN 1411-8890

[2] Hari Prasetijo dan Sugeng Waluyo, "Optimasi Lebar Celah Udara Generator Axial Magnet Permanen Putaran Rendah 1 Fase", JNTETI, Vol. 4, No. 4, November 2015

[3] Mirza Fata Alam, Tedjo Sukmadi, dan Susatyo Handoko, "Simulasi Pengaruh Ketebalan Yoke Rotor, Jarak Antar Kutub Dan Jenis Material Magnet Permanen Terhadap Rapat Fluks Pada Generator Sinkron Fluks Aksial", TRANSIENT, VOL. 2, NO. 3, September 2013

[4] Aris Budiman, Hasyim Asy'ari,Arief Rahman Hakim. 2012. Desain Generator Magnet Permanen Untuk Sepeda Listrik. Jurnal Emitor Vol. 12 No. 01:59-67

[5] Mashar, A. 2011, "Mesin Listrik II." Bandung: Politeknik Negeri Bandung.

[6] Prisandi, C.H., "Studi Desain Kumparan Stator Pada Generator Magnet Permanen Fluks Aksial Tanpa Inti Stator", Fakultas Teknik UI, 2011

[7] P. Salminen, J. Pyrhönen, M. Niemelä, " $A$ Comparison Between Surface Magnets And Embedded Magnets In Fractional Slot Wound Pm-Motors", ISEF 2003 11th International Symposium on Electromagnetic Fields in Electrical Engineering Maribor, Slovenia, September 18-20, 2003 